\title{
Corpo, gênero e maternidade: algumas relações e implicações no cuidado em saúde
}

Recebido em: 07/06/2010

Aceito em: 17/12/2010
Dagmar Elisabeth Estermann Meyer ${ }^{1}$

Apoiada nos Estudos Culturais e de Gênero pós-estruturalistas, discuto processos contemporâneos de significação do corpo em conexão com as noções de "vida boa" "e "felicidade", na perspectiva proposta por Ayres, tomando o corpo como lócus e operador de cuidado em saúde. Baseando-me em resultados de pesquisas, indico a necessidade de nos perguntarmos mais seguidamente: diferenças de gênero e sexualidade podem interferir em relações de cuidado? Como isso pode expressar-se? Como se conecta ao exercício de determinadas formas de poder e de autoridade, no campo da saúde e das relações de cuidado, facilitando e/ou dificultando a "vida boa" e a "felicidade"?

Descritores: Corpo, Gênero, Maternidade, Cuidado, Pós-Estruturalismo.

\section{Body, gender and maternity: some relations and implications in health care}

Grounded on post-structuralist Cultural and Gender Studies, I have discussed about contemporary processes of body signification in connection with notions of 'good life' and 'happiness', from the perspective proposed by Ayres, regarding body as both a locus and an operator of health care. Based on research results, I have pointed out the need for asking questions more often such as: can gender and sexuality differences interfere in care relations? How can this be expressed? How does it connect with the exercise of certain forms of power and authority, in the field of health and care relations, either making it easier and/or hindering 'good life' and 'happiness'?

Descriptors: Body, Gender, Maternity, Care, Post-Structuralism.

\section{Cuerpo, género y maternidad: algunas relaciones e implicaciones en el cuidado en salud}

Con el apoyo de los Estudios Culturales y de género postestructuralista, analizo los procesos actuales de la significación del cuerpo en relación con las nociones de "buena vida" y "felicidad" en la perspectiva propuesta por Ayres, tomando el cuerpo como un locus y operador de la asistencia en salud. Sobre la base de los resultados de la investigación, indico la necesidad de preguntar más veces: el sexo y la sexualidad pueden interferir con las relaciones de cuidado? ¿Cómo puede expresarse? Cómo conectarse con el ejercicio de ciertas formas de poder y autoridad en el ámbito de las relaciones de cuidado de salud, facilitar y / u obstaculizar la "buena vida" y "felicidad "?

Descriptores: Cuerpo, Género, Maternidad, Cuidado, Post-Estructuralismo.

\section{INTRODUÇÃO}

V ivemos um tempo de evidência dos corpos: nos mais diferentes contextos, situações, matizes e formatos, eles proliferam a nosso redor, capturados em imagens e textos ou ao vivo e em cores. Dessa forma, percepções como "eu sou um corpo", "eu tenho um corpo", "eu faço meu corpo", "eu controlo meu corpo" e "eu cuido do meu corpo" são aceitas e repetidas por nós, sobre nós mesmos e/ou dirigidas por nós aos outros, sem estranhamento e quase como sinônimos. Entretanto, os verbos "ser", "ter", "fazer", "controlar" e "cuidar" não são sinônimos e, nessas frases, remetem a conjuntos de sentidos com implicações muito diversas, ambíguas e conflitantes sobre como nos relacionamos e vivemos isso que chamamos de "nossos corpos".
Falado, invadido, investigado e (res)significado por múltiplas áreas do conhecimento e, ao mesmo tempo, assumido tanto como o último reduto de nossa identidade quanto como commodity que vende saúde e beleza, o corpo coloca-se como epicentro de muitos processos que, por (de)composição, interferência e (re)composição, buscam formatar sua aparência, (re)construir suas falhas, (re)definir ou potencializar suas funções e prolongar sua existência. Assim, este tempo em que vivemos, enquanto amplia e complexifica os saberes e práticas corporais, permitindo um controle e uma liberdade sem precedentes sobre/do corpo, também desestabiliza profundamente nossas referências sobre o que ele é e como pode ser conhecido e vivido.

Cada vez mais, deparamo-nos com perguntas como: afinal,

1 Enfermeira e Doutora em Educação. Professora Associada na Faculdade de Educação da UFRGS. Pesquisadora Integrante do Grupo de Estudos de Educação e Relações de Gênero (www.geerge.com) e Bolsista de Produtividade em Pesquisa do CNPq.

* Versão modificada e atualizada de texto originalmente apresentado no $57^{\circ}$ Congresso Brasileiro de Enfermagem, realizado em Goiânia/GO, no período de 3 a 7 de novembro de 2005. 
o que é mesmo o corpo humano? $\mathrm{E}$, de forma muito mais contundente, o que é mesmo o sujeito humano? No contexto dessas interrogações, entretanto, muitas vertentes científicas e filosóficas continuam partilhando uma visão datada elocalizada de sujeito humano, tematizando-o como ser constituído por duas características opostas, que geralmente se expressam pelas seguintes dicotomias: alma/corpo, mente/corpo, pensamento/extensão, razão/paixão, psicologia/biologia. Esse pensamento dicotômico, segundo algumas teorizações póscríticas, hierarquiza e classifica os dois termos da oposição, de modo que um deles - nesse caso, sempre o polo oposto ao corpo - se torna o termo privilegiado e o outro, apresentado como sua contrapartida suprimida, subordinada ou negada, é localizado fora do corpo ou em tudo que o corpo não é, devendo ser controlado para manter sua integridade ${ }^{(1)}$. Assim, as frases com que iniciei o texto nos inserem em um processo de significação ativo, conflituoso e instável que, enquanto funde nossa humanidade e nossa identidade no corpo, as posiciona fora e acima dele e do mundo, apresentando-as como instância que modela, gere e conduz suas capacidades. É no contexto desses processos contemporâneos de significação do corpo que pretendo pensá-lo como lócus e operador de cuidado em saúde, em conexão com gênero e sexualidade.

Cuidado é assumido, aqui, conforme propõe Ayres ${ }^{(2)}$, como um encontro, ou série de encontros, entre um profissional de saúde e um usuário ou, mais amplamente, entre um grupo de profissionais e uma população usuária - e, eu acrescentaria, de um indivíduo consigo mesmo. Com o cuidado, pretende-se, ao mesmo tempo, "(re)conhecer, esclarecer e (re)construir não apenas as necessidades de saúde", mas aquilo "como sendo a boa vida e o modo moralmente aceitável de buscá-la"(3:550). A noção de boa vida conecta-se, nesse contexto, a outra noção - a de felicidade: "Experiências vividas, valoradas positivamente, [...] que, frequentemente, independem de um estado de completo bem-estar ou de perfeita normalidade morfofuncional"(3:551).

É importante esclarecer que as noções de boa vida e de felicidade aqui são assumidas como noções "sob rasura", que não se podem tomar como definições universais constitutivas de uma utopia a ser buscada por todos/as indistintamente, sendo fundamentais para que certas questões-chave de nossos cotidianos profissionais e de nossas vidas possam ser pensadas e tematizadas ${ }^{(4)}$.

Ayres $^{(3: 551)}$ define boa vida e felicidade como "ideias ética e moralmente norteadoras [...] construídas a partir da percepção do valor para a vida humana de determinadas ideias ou práticas a partir do momento, e na exata medida, em que essas são obstaculizadas e negadas por alguma experiência concreta". Nesse sentido, podemos considerá-las como contingentes, provisórias e localizadas, pois inscrevemos seus sentidos em um dado tempo, lugar e circunstâncias que configuram limites e possibilidades concretos para sua compreensão e utilização. O autor autoriza-me essa apropriação quando alerta que considerá-las na perspectiva que ele propõe é indispensável para "evitar um de dois tipos igualmente indesejáveis de fundamentalismo", que, acrescento, são frequentemente praticados na área da saúde: "O de querer determinar de modo objetivo e universalista o que seja [boa vida e] felicidade" de e para os outros; "Num outro extremo, estaria um idealismo excessivamente abstrato, descolado das experiências vividas", presente, por exemplo, na definição de saúde da OMS. "A felicidade não pode ser vista, enfim, como um bem concreto, uma entidade, mas ela tampouco é utopia", diz ele, argumentando que "a experiência da felicidade, ou de sua falta, é uma vivência bastante concreta. Mas [...] não se deixa medir por nada fora dela, e ao mesmo tempo está em estreita relação com tudo aquilo pelo qual buscamos dimensioná-la, como uma espécie de 'bússola existencial', que nos dá o norte sem ser o norte. A felicidade nunca deixa de fazer notar sua falta e, por sua ausência, algo que nos está faltando"(3:551).

Tomando essas noções de cuidado e de felicidade como referências, pretendo discutir um exemplo composto a partir de nossas pesquisas, com 0 qual se pode problematizar determinadas relações entre corpo, gênero e maternidade naturalizadas e/ ou socialmente sancionadas que estão entranhadas em nossa vida e, sobretudo, nos saberes e práticas profissionais que assumimos e realizamos. Penso que esse exercício pode delinear um campo de possibilidades significativo para reflexão e intervenção de cuidadores/as na área da saúde.

\section{Corpo, gênero e sexualidade:}

alguns subsídios conceituais para pensar relações de cuidado

Nicholson ${ }^{(5: 9)}$ defende a ideia de que "a sociedade forma não só a personalidade e o comportamento, mas também as maneiras como o corpo aparece", sendo esse processo inseparável do exercício de formas variadas de poder. Dessa perspectiva, o corpo é assumido como uma variável construída na interseção entre aquilo que herdamos geneticamente e aquilo que aprendemos ao nos tornarmos sujeitos de determinada cultura ${ }^{(6)}$. Aqui, interseção é diferente de adição: não se supõe que a cultura seja adicionada a uma natureza preexistente, mas que ambas se imbricam, produzindo uma materialidade invadida, nomeada, descrita e moldada em processos de significação - nesse caso, de gênero e sexualidade - que configuram os mundos plurais onde vivemos e nos movimentamos.

O corpo é percebido e vivido de forma conflituosa e ambígua, de maneira que os modos de vivê-lo envolvem, simultaneamente, disciplinamento, coerção, subordinação, saúde, libertação, gozo e prazer. Entendendo-o dessa forma, admite-se a existência de importantes nexos entre corpo, diferença e identidade. Nesse sentido, ele é considerado, aqui, 
como um tema/objeto de reflexão no campo da saúde. "Os diferentes discursos - da Igreja, ciência, lei, padrões estéticos, saúde, entre outros - habitam corpos"(7:89); ao habitá-los, esses corpos ancoram nossas identidades. "Os corpos são o que são na cultura" - eles e as marcas que lhes são impressas são "decisivas para dizer do lugar social de um sujeito", pois as marcas culturais "distinguem sujeitos e se constituem como marcas de $\operatorname{poder}^{\prime \prime(7: 75-6)}$. Os processos que significam e inscrevem marcas nos corpos, em diferentes espaços e tempos, são, porém, incapazes de neles fixar, para sempre, um conjunto verdadeiro, definido e homogêneo de marcas/sentidos: "A significação que se atribui aos corpos é arbitrária, relacional, e é, também, disputada", e seus movimentos "são tramados e funcionam através de redes de poder"(7:89). Isso remete diretamente a uma divisão em todos os agrupamentos humanos conhecidos até hoje que, exatamente por isso, é usualmente "compreendida como primeira, originária ou essencial, e quase sempre relacionada ao corpo"(7:76) - ou seja, a divisão masculino/ feminino, que nos insere nas redes de significação de gênero.

Nessas redes, a sociedade e a cultura ocidentais, lato sensu, têm buscado investir de forma mais incisiva, desde o século 18, em certa "coerência e continuidade entre sexo - gênero - sexualidade", que sustenta a legitimação de uma forma normal de vida em sociedade, cuja base seria a família (mononuclear moderna). Essa, "por sua vez, se sustenta sobre a reprodução sexual [e social] e, consequentemente, sobre a heterossexualidade"(7:88). Tal forma de articulação entre corpo, gênero e sexualidade não é, pois, natural e universal, tornando-se inteligível e operante no interior de redes de poder que a definem e que permitem que funcione como tal.

Desdobrando um pouco mais essas afirmações sobre gênero e sexualidade ${ }^{(8)}$, considera-se que, ao longo da vida e através das mais diversas instituições e práticas sociais, nos constituímos como homens e mulheres, num processo que não é linear, progressivo nem harmônico e que também nunca está completo. Além disso, sinaliza-se que não há uma relação de causa e efeito entre gênero e sexualidade, ou seja, homens e mulheres podem viver de diferentes formas seus desejos e prazeres sexuais. A heterossexualidade é apenas uma dessas formas e não é constitutiva da masculinidade e da feminilidade: vivem-se formas de masculinidade e feminilidade não-heterossexuais.

Inscreve-se, nesse pressuposto, uma articulação intrínseca entregênero, sexualidadeeeducaçãoe também uma ampliação da noção de educativo; entende-se que educar engloba um complexo de forças e de processos em que indivíduos são transformados em - e aprendem a se reconhecer como homens e mulheres nas sociedades e grupos a que pertencem. Argumenta-se que esses processos envolvem estratégias sutis e refinadas de naturalização e legitimação que precisam ser reconhecidas e problematizadas. Então, exatamente porque gênero significa o sexo e enfatiza a pluralidade e o conflito entre os processos pelos quais a cultura constrói e distingue corpos e sujeitos femininos e masculinos, torna-se necessário considerar que isso se expressa pela articulação de gênero com outras "marcas" sociais, como classe, raça/etnia, sexualidade, geração, religião, nacionalidade. Ainda, cada uma dessas articulações produz modificações importantes nas formas como feminilidades e masculinidades, no plural, são (ou podem ser) vivenciadas por grupos diversos, dentro dos mesmos grupos ou pelos mesmos indivíduos, ao mesmo tempo ou em diferentes momentos da vida. Essa noção de gênero também supõe que nossas análises e intervenções tomem como referência as relações - de poder - entre mulheres e homens e as muitas formas sociais e culturais que os constituem como "sujeitos de gênero e sexuais". Isso implica, portanto, analisar processos, estratégias, saberes e práticas sociais e culturais que educam indivíduos como mulheres e homens de determinados tipos, sobretudo se quisermos investir em intervenções que permitam modificar, minimamente, as relações de poder de gênero vigentes nas sociedades e grupos em que vivemos.

É a partir de desdobramentos dessa forma de analisar as relações entre corpo, gênero e sexualidade que apresento, a seguir, um exemplo composto como fruto das pesquisas, focalizando especificamente a maternidade. Encaminho, ao fim, o exercício de pensar suas implicações para o cuidado em saúde com perguntas que ficarão em aberto, deixando a cada leitor o desafio de pensar possíveis respostas para elas nos diferentes contextos em que cada um vive e trabalha.

\section{Pedagogias da maternidade - cuidado em saúde e o imperativo do amor e da doação}

Corpos grávidos e maternos têm-se constituído como territórios de biopolíticas contemporâneas, e a análise desse processo tem se desdobrado em várias pesquisas que fazemos desde 2000. Nelas, discutimos alguns enunciados sobre maternidade que circulam em múltiplas instâncias e artefatos de nossa cultura.

Apresentados como se fizessem parte da natureza das mulheres que se tornam mães, os atributos e valores que tais enunciados instituem são produzidos, ampliados e atualizados pelos discursos científicos e já fazem parte do senso comum. Por isso, eles também norteiam muitos dos processos educativos em que nos tornamos mulheres e homens e/ou mães e pais de determinados tipos, e sua força reside nas múltiplas, sutis e sempre renovadas possibilidades de repetição. Educação e saúde são dois dos campos de conhecimentos e práticas que produzem, atualizam e repetem o que a mãe é ou deve ser, e sua "autoridade científica" constitui importante estratégia de naturalização e universalização de tais definições.

Comento, aqui, uma imagem que "ilustra" a reportagem de capa de uma revista que apresenta resultados de estudos científicos experimentais sobre eventos da reprodução humana 
e da relação mãe e filho ${ }^{(9)}$. Ao discuti-la, não focalizo sua veracidade científica, nem os resultados estritos desse estudo, mas procuro entender como determinados conhecimentos - que se apresentam e que assumimos como científicos, universais e neutros - incorporam, reproduzem, atualizam e tencionam representações culturais de maternidade e quais efeitos isso pode ter nos modos como cuidamos de mulheres e homens em nosso cotidiano profissional.

Na capa da revista e na reportagem, a imagem da Virgem Maria (uma das mais poderosas representações do que a mãe é ou deve ser) foi conectada a um estudo de manipulação neonatal com ratos que relaciona fatores de estresse vivenciados logo após o nascimento e a infertilidade na vida adulta. Com o título "Ecos da Separação", apresentamse resultados indicando, entre outras coisas, que o "estresse gerado por breves ausências da mãe nos dias seguintes ao parto lesa o cérebro de animais de laboratório e provoca infertilidade nos filhotes"(10:34). Explica-se que essas ausências não se referem a um afastamento traumático, mas apenas a interrupções "momentâneas, quase inofensivas, do estreito convívio mãe-filho que se estabelece nos dias seguintes ao nascimento" e que, "durante esses 120 segundos diários em que ficaram longe da mãe, os ratinhos permaneceram gentilmente alojados nas mãos enluvadas de um pesquisador"(10:36).

A ilustração do texto com três imagens diferentes da Virgem Maria opera um movimento de significação em direção contrária à do alerta do que "seria temerário especular, num exercício de simples transposição mecânica, que os danos cerebrais verificados em animais - e os problemas sexuais e reprodutivos decorrentes dessas lesões - também devam ocorrer em bebês humanos"(10:34), reforçando a dedicação exclusiva e a presença física e psíquica ininterruptas como dimensão central do exercício de uma maternidade bemsucedida entre humanos. Esses efeitos de poder da imagem visibilizam-se no texto, que afirma que os pesquisadores vêm procurando medir, por exemplo, possíveis efeitos negativos "da pouca interação entre mães com depressão pós-parto e seus filhos recém-nascidos", porque essa situação guarda "alguma semelhança com o experimento de manipulação neonatal feito com ratos"(10:37).

Em outro estudo, Schwengber ${ }^{(11)}$ analisou a revista Pais $e$ Filhos, explorando alguns modos pelos quais os discursos de promoção da saúde investem no corpo grávido para constituílo como um "corpo-ambiente" saudável, no qual a moral do alimentar-se bem surge como umas das formas importantes de controle e regulação de "dois corpos em um". Schwengber demonstra como a norma que regula o aumento de peso na gestação vem se modificando historicamente: hoje ela é, no máximo, de 6 a 9 quilos; há uma ou duas décadas, era de 12 a 15, enquanto anteriormente era considerado normal engordar mais de 20 quilos.

Em consonância com isso, cuidados corporais vinculados a programas regulares de exercícios corporais constituem um repertório importante das orientações do pré-natal de gestantes na contemporaneidade, mesmo que, ao

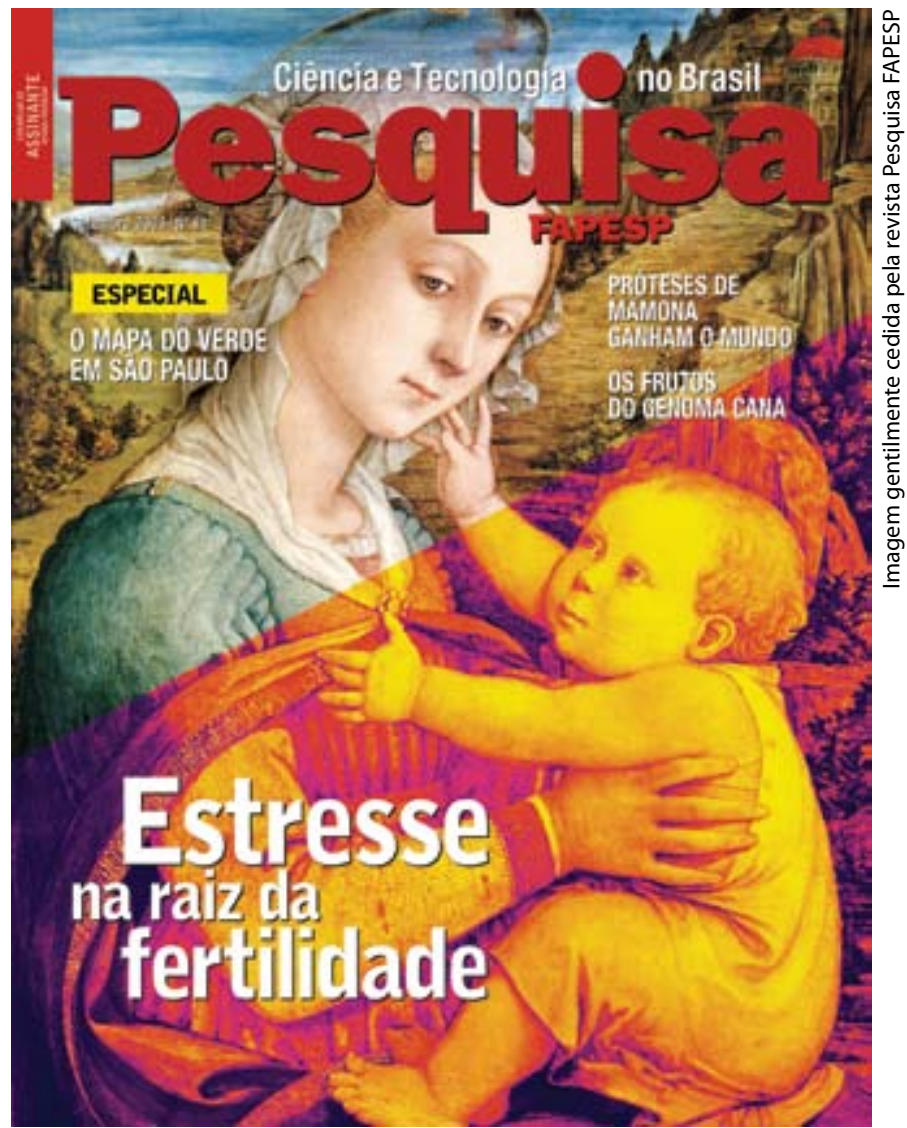

longo do tempo, essa indicação não tenha aparecido tão claramente. Algumas de nós ainda conseguem lembrar-se de algumas práticas corporais que durante muito tempo foram consideradas não condizentes com a gravidez e que, por isso, eram desaconselhadas. Hoje, o que se ouve é: "Exercitar-se durante a gravidez não é apenas saudável como é importante. [...] Evita excesso de peso, melhora a postura, a oxigenação do feto... faz com que a mulher tenha um parto mais facilitado e uma recuperação pós-parto muito mais rápida. Ou seja: livre-se dos tabus e garanta o seu bemestar e o do seu filho"(11:6). É importante destacar que esse discurso interpela as mulheres em sua condição de mães que devem gestar e parir crianças saudáveis; aquelas que não se mobilizam para fazer as escolhas certas são posicionadas como mães de risco - uma linguagem que produz sujeitos que se tornam alvos de práticas educativas e de intervenção mais sistemáticas e estandardizadas ${ }^{(9)}$.

O exame do Programa Nacional de Aleitamento Materno é também um excelente exemplo para discutirmos como representações de gênero atravessam e constituem formas científicas (e outras maneiras) de conhecer ${ }^{(12)}$ e instituem poderosas redes de conformação e controle de corpos maternos contemporâneos. Reproduzo, aqui, um enunciado bastante usado nestes tempos de valorização de corpos magros, com o qual se informa às mulheres que as 
nutrizes têm elevada eficiência energética, produzindo leite sempre, mesmo com ingestão calórica limitada. Traduzindo: "amamentar emagrece" e, sobretudo, "não existe leite materno fraco". Almeida(13:67), ao detalhar a composição do leite materno, esclarece que a concentração de minerais do leite não é afetada pela dieta da mãe. Na prática, isso pode significar que, "quando os níveis baixam a patamares que significam situação de maior gravidade, as reservas maternas são literalmente depletadas, chegando, em casos extremos, à decomposição de tecidos [...] para manutenção dos níveis de minerais no leite". Assim, sob determinadas condições especialmente as de pobreza e desnutrição, que imperam em países pobres e nas populações excluídas dos benefícios da globalização -, amamentar pode comprometer seriamente a saúde das mães, um aspecto que jamais vi mencionado em qualquer dos materiais educativos que analisei.

\section{...e para terminar: como cuidado, vida boa e felicidade se relacionam com isso?}

Considerando o exemplo aqui composto e os conceitos antes discutidos, poderíamosentão perguntar:comonaturalizações que estabelecem diferenças de gênero e de sexualidade impactam relações de cuidado quando essas colocam sujeitos em posições diferenciadas de poder? Como essas naturalizações atravessam e legitimam os conhecimentos que produzimos e as práticas de saúde que eles sustentam? Como elas incidem sobre o corpo, produzindo-o de determinados modos, com que efeitos e para quem? Ainda: como essas relações de poder se conectam, facilitando e, em alguns casos, até mesmo legitimando o exercício de determinadas formas de poder e de autoridade, no campo da saúde e das relações de cuidado, que podem se constituir como obstáculos para a vida boa e a felicidade? Essas são algumas das questões que se colocam para quem trabalha com tais noções, considerando-as como construções discursivas instituídas e instituidoras de relações de poder, algumas delas colocadas como indagações e problemas antes impensáveis.

Nesse sentido, mais do que colocar-me na posição de quem prescreve o que se pode ou se deveria fazer para construir relações de cuidado mais promissoras, sugiro que tais questões possam instigar nosso pensamento e nossa inventividade, ajudando-nos a estranhar o que aceitamos como familiar e a familiarizar-nos com aquilo e aqueles que costumamos estranhar. Esse exercício tem nos instigado a olhar de fora, como se não conhecêssemos as teorias e práticas que nos constituem tão profundamente que nem as percebíamos mais como apre(e)ndidas. Essa é uma das possibilidades que se abrem com essas abordagens: a de nos (re)inventarmos enquanto sujeitos de gênero e sexuais e, de forma articulada a isso, (re)inventarmos algumas das práticas de educação e de saúde que se constituem como instâncias dessas atribuições. Penso que isso incide sobre o cuidado e o potencializa como um encontro entre sujeitos que, além de estarem seriamente empenhados em investir na melhoria das condições de saúde - a própria e a do outro -, promovem possibilidades concretas de vida boa e de felicidade.

\section{Referências}

1.Grosz E. Corpos reconfigurados. Cad Pagu. 2000;14:45-86.

2. Ayres JRM. Cuidado e reconstrução das práticas de saúde. Interface Comun Saúde Educ. 2004;8(14):73-91.

3. Ayres JRM. Hermenêutica e humanização das práticas de saúde. Ci Saúde Coletiva. 2005;10(3):549-60.

4. Hall S. Quem precisa de identidade? In: Silva TT, organizador.

Identidade e diferença. $4^{\mathrm{a}}$ ed. A perspectiva dos estudos culturais.

Petrópolis: Vozes; 2005.

5. Nicholson L. "Interpretando o gênero". Rev Estud Fem. 2000;8(2):9-42.

6. Meyer D, Soares R. Corpo, gênero e sexualidade: um início de reflexão.

In: Meyer D, Soares R, organizador. Corpo, gênero e sexualidade.

Porto Alegre: Mediação; 2004.

7. Louro G. Um corpo estranho. Ensaios sobre sexualidade e teoria queer.

Belo Horizonte: Autêntica; 2004.
8. Meyer D. Teorias e políticas de gênero: fragmentos de histórias e desafios

atuais. Rev Bras Enferm. 2004;57(1):13-8.

9. Meyer D. Educação, saúde e politização da maternidade: olhares desde

a articulação entre estudos culturais e estudos de gênero. In: Silveira RH.

Cultura, poder e educação. Canoas: Ed. ULBRA; 2005.

10. Pivetta M. Ecos da separação. Rev Ciênc Tecnol Bras. 2004;99:34-9.

11. Schwengber SV. Mãe mais que perfeita é aquela que mantém

a forma sem prejudicar o bebê. Anais do XIV Congresso Brasileiro

de Ciências do Esporte (Combrace). Porto Alegre: UFRGS, de 4 a 9 de

setembro de 2005, p. 11

12. Meyer $D$, Oliveira D. Breastfeeding policies and the production of motherhood: a historical-cultural approach. Nurs Inq. 2003;10(1):11-8. 13. Almeida JA. Amamentação. Um híbrido natureza-cultura. $2^{\mathrm{a}}$ ed. Rio de Janeiro: Fiocruz; 1999. 